\title{
NOVEL APPLICATION OF FOCUSED ION BEAM ELECTRON MICROSCOPY (FIB-EM) IN PREPARATION AND ANALYSIS OF MICROFOSSIL ULTRASTRUCTURES: A NEW VIEW OF COMPLEXITY IN EARLY EUKARYOTIC ORGANISMS
}

\author{
JAMES D. SCHIFFBAUER* and SHUHAI XIAO \\ Department of Geosciences, Virginia Polytechnic Institute and State University, 4044 Derring Hall, Blacksburg, Virginia 24061, USA \\ e-mail: jdschiff@vt.edu
}

\begin{abstract}
Coupled dual-beam focused ion beam electron microscopy (FIB-EM) has gained popularity across multiple disciplines over the past decade. Widely utilized as a stand-alone instrument for micromachining and metal or insulator deposition in numerous industries, the submicron-scale ion milling and cutting capabilities of FIB-EM systems have been well documented in the materials science literature. These capacities make FIB-EM a powerful tool for in situ, site-specific transmission electron microscopy (TEM) ultrathin foil preparation. Recent advancements in the field-emission guns (FEGs) of FIB-EM systems have provided spatial resolution comparable to that of many high-end scanning electron microscopes (SEM), thus providing enhanced imaging capacities with material deposition and material removal capabilities. More recently, FIB-EM preparation techniques have been applied to geological samples to characterize mineral inclusions, grain boundaries, and microfossils. Here, we demonstrate a novel method for analyzing three-dimensional (3D) ultrastructures of microfossils using FIB-EM. Our method, FIB-EM nanotomography, consists of sequential ion milling, or cross sectioning, and concurrent SEM imaging. This technique with coupled dual-beam systems allows for real-time, 3-D ultrastructural analysis and compositional mapping with precise site selectivity and may provide new insights in fossil ultrastructures. Using the FIB-EM nanotomography method, we investigated herkomorphic and acanthomorphic acritarchs (organicwalled microfossils) extracted from the $\geq 999$ Ma Mesoproterozoic Ruyang Group of North China. The 3-D characteristics of such important but controversial acritarch features as processes and vesicularly enclosed central bodies are described. Through these case studies, we demonstrate that FIB-EM nanotomography is a powerful and useful tool for investigating the three-dimensionality of microfossil ultra- and nanostructures.
\end{abstract}

\section{INTRODUCTION}

During the 1950s, argon ion milling techniques became popularized as a means of thinning mineral samples to electron transparency for use in transmission electron microscopy (TEM), revolutionizing the microstructural study of Earth science materials (Castaing and Labourie, 1953; Barber, 1970; Heaney et al., 2001). The increased use of ion milling in preparing rock samples for TEM analysis was a direct result of the inadequacy of standard ultramicrotomy and electropolishing techniques - commonly used for biological samples and alloys or metals, respectively - when applied to Earth science materials. As many Earth science materials are inherently brittle and friable, argon milling grew into the principal methodology for preparing Earth science TEM samples (Barber, 1999; Heaney et al., 2001 and references therein). Since the 1990s, however, there has been an increasing utilization of a different tool-focused ion beam workstations. Newer dual-beam FIB-

* Corresponding author.

Copyright $\odot$ 2009, SEPM (Society for Sedimentary Geology)
EM workstations are built on field emission scanning electron microscopy (FE-SEM) platforms, and couple a high-resolution, highmagnification field emission gun (FEG) with a focused ion beam consisting of a gallium $\left(\mathrm{Ga}^{+}\right)$liquid metal ion source (LMIS). Recent advancements in imaging technologies have resulted in FEGs capable of subnanometer-scale imaging; these technologies are now commonly incorporated into FIB-EM workstations.

TEM sample preparation was the original high-end use for these instruments (e.g., Giannuzzi et al., 1998, 1999; Heaney et al., 2001; among numerous others). The integrated SEM in dual-beam systems allows the operator to have visual control on where and how the sample is milled, as well as perspective when using an integrated micromanipulator probe needle in TEM foil lift-outs. Conversely, single-beam FIB systems rely on the ion beam for both milling and imaging, which is intrinsically detrimental to the sample. The principal advantages of dual-beam systems, therefore, is that they not only allow for simultaneous electron imaging and ion milling but also circumvent surficial damage to the sample caused by extended ion imaging in single-beam systems.

While the semiconductor industry has dominated the FIB-EM-use market for the creation and modification of prototype microdevices, the capacities of FIB-EM instruments have promoted their expansion into multiple industrial and research laboratories and have vastly diversified the types of materials examined. The primary functions of FIB-EM instruments are the dissection and deposition of material on the microto nanometer scale using controlled and automated $\mathrm{Ga}^{+}$focused ion beam rastering. These systems have been successfully used to prepare site-specific TEM foils of numerous specimens, ranging from metals, alloys, and ceramics, to biological samples, Earth and planetary materials, and fossils (e.g., Giannuzzi et al., 1999; Heaney et al., 2001; Weiss et al., 2002; Lee et al., 2003; Floss et al., 2004; Wirth, 2004, 2009; Benzerara et al., 2005; Kempe et al., 2005; Bernard et al., 2007; Cavalazzi, 2007; Marko et al., 2007). TEM foil preparation with the FIB-EM technique has drastically changed and vastly improved traditional ultramicrotomy-based TEM specimen preparation, because it allows site-specific ultrathin foil preparation and introduces no ultramicrotomy-induced deformation artifacts. No longer is this instrument considered to be only a TEM sample preparation machine. They are now regarded as comprehensive micromachining platforms and are fully capable of carrying out integrated analyses. FIB-EM systems are now being utilized as stand-alone analytical instruments and are starting to gradually infiltrate various research fields as they become increasingly accessible.

FIB-EM systems are ideal, all-in-one workstations for analyzing intricate details of microfossils because of their capabilities - whether the fossils are embedded in their host rock or extracted. Microfossil ultrastructural analysis is certainly not outmoded. Since the early days of systematic microfossil investigation using standard TEM procedures (e.g., Oehler, 1976, 1978; Schopf and Oehler, 1976), the study of microfossil ultrastructure has developed into an integral step in aiding 
the taxonomic interpretation of Proterozoic and Phanerozoic microfossils (Talyzina and Moczydłowska, 2000; Javaux et al., 2003, 2004; Kempe et al., 2005; Javaux and Marshal, 2006; Willman and Moczydłowska, 2007; Cohen et al., 2009).

In this study, we used a FIB-EM system to examine the ultrastructures of Mesoproterozoic acritarchs from the Beidajian Formation of the Ruyang Group, southern Shanxi, North China (Xiao et al., 1997). While the age of the Ruyang Group is constrained poorly, it is probably $<1625 \mathrm{Ma}$ and $\geq 999 \mathrm{Ma}$, and likely between 1300 1400 Ma based on C-isotope profiles (Xiao et al., 1997). Acritarchs are organic-walled vesicular microfossils that cannot be placed with confidence into any existing classification (Evitt, 1963). These microfossils undoubtedly have diverse biological affinities and, therefore, should be considered a polyphyletic grouping with no true taxonomic status or rank (Servais, 1996). Predominantly interpreted as planktonic protists, acritarchs are widely known from the Proterozoic Eon. Unambiguous acritarchs are as old as 1600-1800 Ma (Yan, 1982, 1991, 1995; Luo et al., 1985; Zhang, 1986, 1997; Sun and Zhu, 2000), although possible graphitized vesicles from high-grade metamorphic rocks of Australia and China may place their earliest appearance in the late Archean (ca. $2500 \mathrm{Ma}$ ) (Schiffbauer et al., 2007; Zang, 2007).

The identification of taxonomically and phylogenetically useful features in acritarchs can be challenging because they may include a diverse range of organisms - diapause egg cases of early metazoans (Yin et al., 2007; Cohen et al., 2009), resting cysts of prasinophyte chlorophytes (Arouri et al., 1999), dinoflagellates (Moldowan and Talyzina, 1998; Meng et al., 2005; Willman and Moczydłowska, 2007), to various prokaryotes (Javaux et al., 2003). Traditionally, some acritarchs are interpreted as eukaryotic fossils based on their relatively large cell size (Schopf, 1992), as large cell size was also used to support a eukaryotic interpretation for the ca. 1900 Ma megafossils Grypania spiralis (Han and Runnegar, 1992). Then again, size may not be an adequate indicator of taxonomic standing for single-celled organisms, as some prokaryotes may reach extremely large sizes, such as the 750$\mu \mathrm{m}$-diameter Thiomargarita namibiensis (Schulz et al., 1999). In light of this, microstructures and ultrastructures are often sought to elucidate taxonomic interpretations of acritarchs (Arouri et al., 1999, 2000; Talyzina and Moczydłowska, 2000; Javaux et al., 2004). For example, micro- and ultrastructural characterization of ca. 1500 Ma acanthomorphic (or process-bearing) acritarchs using both SEM and TEM techniques has provided unambiguous evidence of cytoskeletal sophistication (Javaux et al., 2001, 2003, 2004), presenting the earliest unquestionable fossil evidence for the presence of eukaryotes.

Both SEM and TEM have their shortcomings, however. SEM only provides surface morphology and compositional information, and TEM requires time-consuming microtomy that allows little control on the orientation of ultrathin sections relative to the microfossil. The FIB-EM technology offers considerable benefits over TEM, including minimal sample preparation and continuous sectioning in real time with highprecision site-selectivity. Its operational capabilities as a stand-alone analytical instrument, however, remain relatively underutilized outside of materials sciences research and the semiconductor manufacturing industry. Here, we illustrate a novel method for analyzing ultrastructures of fossil specimens using FIB-EM, which entails sequential ion-beam-milled cross sections imaged via integrated FE-SEM, generating a form of in situ highresolution three-dimensional microscopy — or FIB nanotomography.

The FIB nanotomography technique is accomplished by sequential ion sectioning and subsequent acquisition of scanning electron micrographs of the each serial section of the structure of interest. The FIB tomographic technique has been widely used in materials sciences to study materials interfaces in, for instance, ceramics, alloys, composites, cements, and particulates (Inkson et al., 2001; Holzer et al., 2004, 2006, 2007; Kubis et al., 2004; Groeber et al., 2006). The interslice spacing for sequential sections in the FIB-tomographic method from the published materials literature typically ranges from
10-300 $\mathrm{nm}$ and are dependent on the size of the features of interest. The most common increments, based on time-efficiency of the ionsectioning process, are 100-250 nm, although FIB-nanotomography of 100 -nm-sized particles require sectioning as fine as $10 \mathrm{~nm}$ for proper three-dimensional (3-D) reconstructions (Holzer et al., 2004). The application of the FIB nanotomography technique allows for real-time, three-dimensional ultrastructural analysis and compositional mapping with precise site selectivity and may create opportunities for microfossil ultrastructural analyses.

\section{EQUIPMENT, TECHNIQUES, AND PROCEDURES}

\section{Brief Technical Description of FIB-EM System and Operational Capabilities}

The Virginia Tech Institute of Critical Technology and Applied Science Nanoscale Characterization and Fabrication Laboratory (VTICTAS-NCFL) houses a state-of-the-art FIB-EM instrument, the FEI Company's DualBeam ${ }^{\mathrm{TM}}$ Helios $600 \mathrm{NanoLab}^{\mathrm{TM}}$ (Fig. 1A). The large vacuum chamber of the Helios Nanolab can accommodate samples up to $15 \mathrm{~cm}$ in diameter and a Z-depth of $5 \mathrm{~cm}$. Housed within this workstation are the following primary components: a high-resolution, high-magnification Elstar ${ }^{\mathrm{TM}}$ Schottky FEG for scanning electron microscopy (SEM); multiple electron detectors for image acquisition, including a through-the-lens detector (TLD) for ultra-high resolution secondary electron detection (sample surface topography), an EverhartThornley detector (ETD) conventional secondary electron detection, and a backscattered electron detector (BSED) for compositional information; and a high-resolution Sidewinder ${ }^{\mathrm{TM}}$ focused $\mathrm{Ga}^{+}$ion beam column for controlled, nanoscale-material addition and excavation with a Continuous Dynode Electron Multiplier detector (CDM detector) for ion imaging (Figs. 1B-C).

The electron column and ion column are oriented within the workstation so that the electron and ion beams (E-beam and I-beam, respectively) intersect at a $52^{\circ}$ angle at their coincident point (Figs. 2A-B). Both beams can be active simultaneously and operate independently. The E-beam is normally used for nondestructive imaging, whereas the I-beam is used to volatize material in an operator-defined and controlled pattern. Both the electron column and ion column can be operated at a broad range of beam currents and voltages, allowing for optimal imaging and milling capacities on a wide array of samples. The Elstar ${ }^{\mathrm{TM}}$ electron column is capable of 1,000,000 $\times$ magnification, which can provide image detail at $0.9 \mathrm{~nm}$ resolution at a beam voltage of $15 \mathrm{kV}$ and optimum working distance. The Sidewinder ${ }^{\mathrm{TM}}$ ion column can also provide high-resolution images of $5.0 \mathrm{~nm}$ resolution at $30 \mathrm{kV}$ at coincident working distance. Additionally, both beams are highly capable of operating at lower beam energies. This enhances SEM imaging of surface topography by allowing for charge control. Lower energy of the I-beam is useful in removing or reducing surface amorphization during ion imaging as well as material removal. Moreover, precise piezo-control of the 5-axes sample stage permits ease of navigation along the $\mathrm{x}$ - and $\mathrm{y}$-directions as well as rotational movements. Stage tilting and z-axis movement are motorized so that, at eucentric height of the sample or coincident point of the beams, a precise spot on the sample surface can be positioned perpendicularly to the E- and I-beams for synchronized electron imaging and ion milling purposes.

This FIB-EM instrument is capable of nanoscale lithography, deposition, and tomography; and the integrated Omniprobe ${ }^{\mathrm{TM}}$ tungsten micromanipulator probe needle can be utilized for precision probing, straining, moving, and placing nanometer-sized objects cut from or deposited on larger samples. This specific FIB-EM system also utilizes an integrated three-nozzle gas injection system (GIS, Figs. 1BC) with an organometallic gas for platinum deposition and various other material-specific assist gases (or decorative gases) to enhance specialized ion-milling processes, such as insulator enhanced etching 

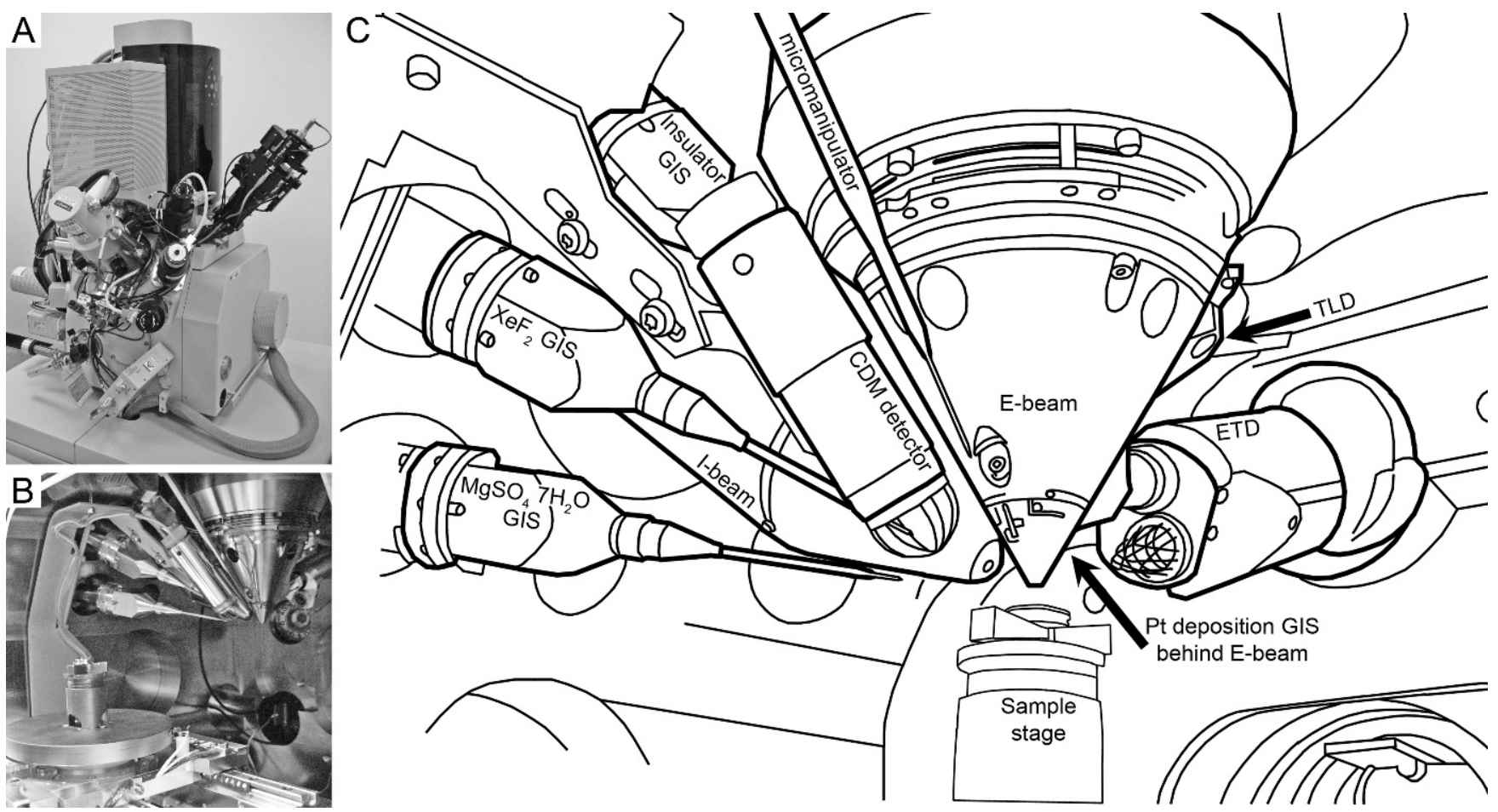

FIGURE 1-FIB-EM instrument photographs and sample chamber schematic with labeled components. A) Photograph of FEI Company's DualBeam ${ }^{\text {TM }}$ Helios 600 NanoLab ${ }^{\mathrm{TM}}$. B) Sample chamber photograph with E-beam, GIS nozzles, CDM detector, and sample stage visible. C) Schematic diagram of sample chamber with E-beam, Ibeam, GIS nozzles, micromanipulator probe needle, and image detectors labeled.

and selective carbon-milling. These GIS nozzles are essentially precisely controlled, $100 \mu \mathrm{m}$-diameter hypodermic needles inserted to within $100 \mu \mathrm{m}$ of the sample surface for delivery of gases in direct proximity to the region of interest. The organometallic platinum gas is crucial for all cutting operations. Platinum is deposited by controlled I-beam volitization of the organic component of the precursor gas and typically accreted to a thickness of one micron on the surface of the sample region of interest. The deposited platinum layer is essential for defining and protecting the original sample surface from superfluous I-beam damage because the I-beam is parabolically shaped. Furthermore, platinum is also used as a binding glue (to the micromanipulator probe needle) when material biopsies or TEM foil lift-outs are performed or constructed. In addition to the deposition of metals, decorative gases can be used. For example, water vapor augments organic material removal, and xenon diflouride gas is used commonly to enhance the volatization of oxides, similar to standard hydroflouric acid etching.

To aid its use as a stand-alone analytical instrument, the Helios 600 workstation system is equipped with Pegasus XM 4 Integrated Energy Dispersive Spectrometer (EDS) and Electron Backscatter Diffraction (EBSD) packages, with the Genesis EDS $x$-ray microanalysis system and Hikari EBSD camera. When coordinated with material removal via the ion beam, it is, therefore, possible to create 3-D reconstructions of the internal structure, chemistry, and orientation of objects just a few nanometers in size.

The principal tasks conducted by FIB-EM workstations are in situ material deposition, nanometer-scale ion milling, and site-specific sample cross sectioning, all of which can be easily monitored in real time via concurrent electron imaging. The FIB-EM's most common use is TEM ultrathin foil preparation, which consists of cutting an electrontransparent foil through ion material excavation and subsequent moving and attaching the sample to a TEM grid via an integrated micromanipulator probe needle. As these ion-sectioning capabilities have submicron-scale positional accuracy, one can clearly understand the advantages of FIB-EM workstations in TEM ultrathin foil preparation. Additional advantages over standard ultramicrotomy include preserving sample structural integrity that would be otherwise damaged by ultramicrotomy and avoiding the introduction of such physical artifacts to the sample as fissures (microcracks), epoxy resin shatter, and knife chatter. The I-beam itself may also introduce such artifacts during ion imaging and cross sectioning as sample surface amorphization with consequent loss of microstructural detail, crosssection curtaining, and $\mathrm{Ga}^{+}$impregnation (Prenitzer et al., 2003; Rubanov and Munroe, 2004). Curtaining, however, is easily resolved during the cross-section cleaning process (or thinning in TEM ultrathin foil preparation), and broad surface amorphization can be avoided with careful selection of beam current and minimal usage of I-beam imaging.

Paleobiological TEM sample preparation via standard ultramicrotomy techniques is prone to causing misinterpretation of fossil microstructure, as defects of sample preparation abound. A major advantage of the FIB-EM technique is that it can cut nearly any material with minimal damage and aberration. The FIB-EM can be used for preparation of the most challenging samples that are not easily prepared by microtome or electropolish techniques, because the material removed by the I-beam is volatized rather than sheared by physical means. Moreover, because of the subnanometer-scale electron imaging capabilities, integrated ion milling, and submicronscale positional accuracy, this instrument is highly applicable to in situ, site-specific, nanometer-scale tomographic analyses. While inherently destructive to the samples analyzed, this mode of tomographic analysis offers spatial and composition information beyond the capacities of standard microcomputed X-ray tomographic techniques.

\section{Sample Description and Preparation for FIB-EM Nanotomography}

The siliciclastic host rocks containing the acritarchs used for this study were collected from the Mesoproterozoic Beidajian Formation of the Ruyang Group ( $\geq 999 \mathrm{Ma}$ ) at the Shuiyougou Section (SYG 6), southern Shanxi, North China (Xiao et al., 1997). Shales and siltstones of the Beidajian Formation contain highly abundant and well-preserved 

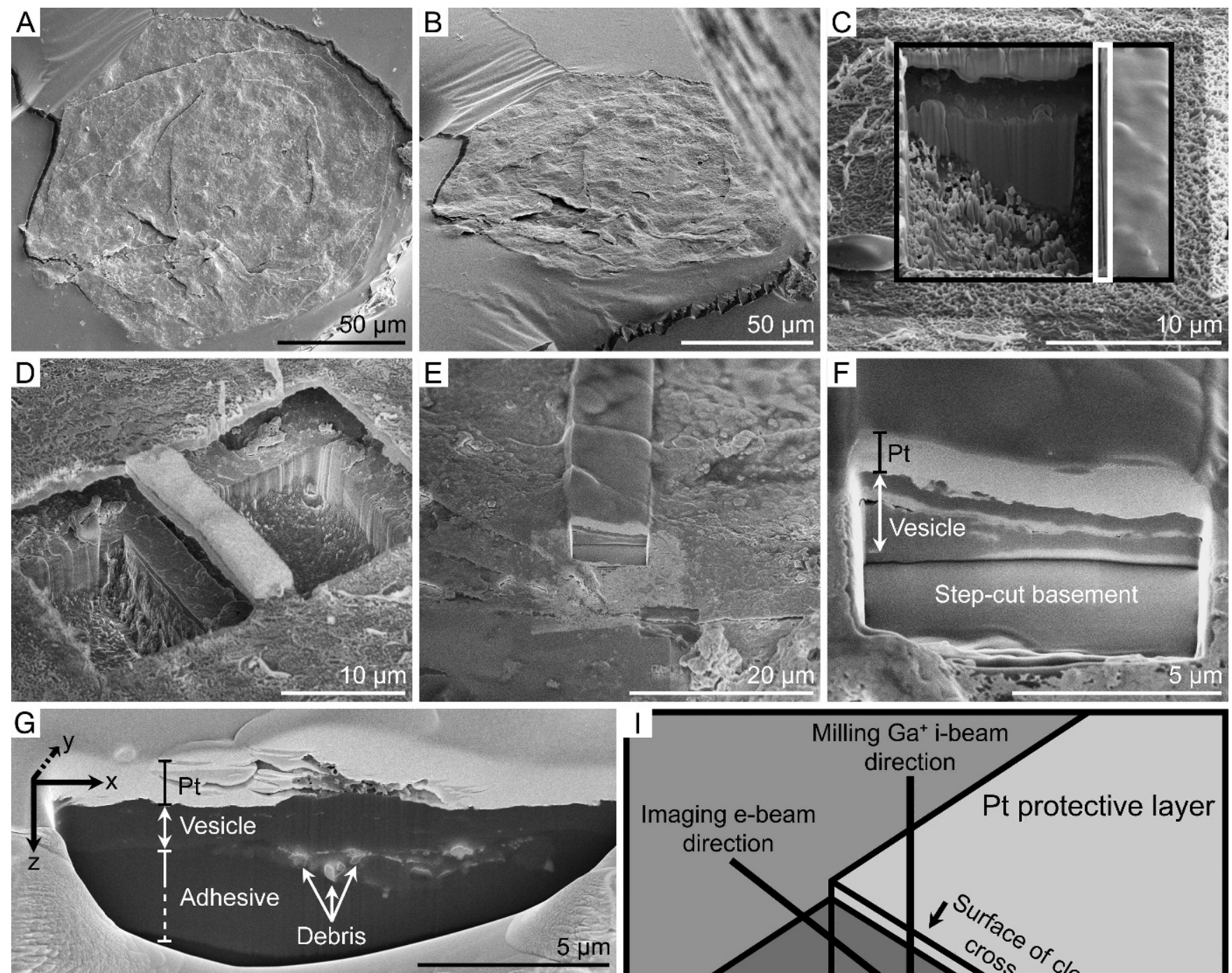

$\mathrm{H}$

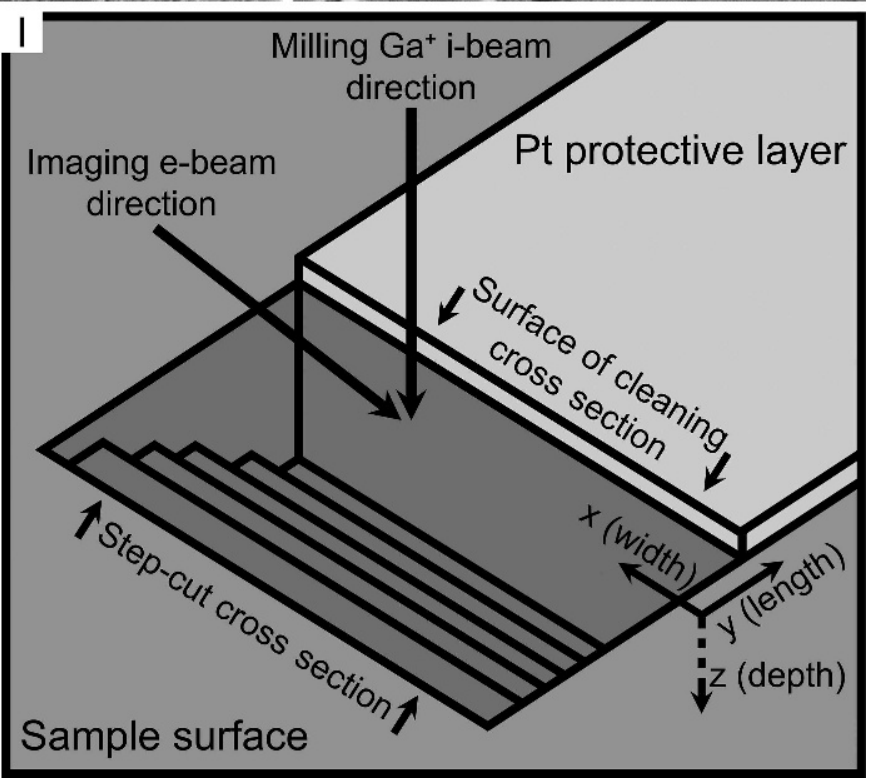

FIGURE 2-Electron micrographs, cross-sectional binary data (BD), and schematic diagram of FIB sample processing. A-F) Dictyosphaera delicata specimens; G-H) Shuiyousphaeridium macroreticulatum specimen cross section and BD of vesicle ultrastructure; I) schematic diagram of FIB sample processing. A) Overview of uncut $D$. delicata specimen perpendicular to E-beam. B) Overview of same D. delicata specimen as shown in (A) oriented perpendicular to I-beam and imaged with E-beam, Pt deposition GIS nozzle visible in upper right corner of frame of view. C) Side view of step-cut into $D$. delicata specimen with Pt deposition pattern (right black box), step-cut pattern (left black box), and cleaning-cross-section pattern (white box). D) Standard TEM lift-out FIB preparation of $D$. delicata specimen, consisting of two opposing step-cuts juxtaposed to Pt protective strip, E) FIB nanotomography preparation of $D$. delicata specimen with initial step-cut at leading edge of Pt deposition. F) Higher magnification view of initial cross section shown in (E), additionally showing multilamellar vesicle wall structure. G) Representative cross section from FIB nanotomography of Shuiyousphaeridium macroreticulatum specimen with axes labeled, triple white arrow indicates debris trapped in the adhesive layer. $\mathrm{H}$ ) Thresholded BD from cross section shown in (G), illustrating reduction of 3-D to 2-D as only cross section axes $\mathrm{x}$ and $\mathrm{z}$ are visible. I) Schematic representation of FIB nanotomography sample processing. Note for Figures 2-4: labeled brackets observed in Figures $2 \mathrm{~F}-\mathrm{G}$ also used in Figures 3 and 4 to indicate deposited platinum protective layer, vesicle wall(s), and underlying adhesive. Pt brackets are black and flat ended; vesicle brackets are white and terminated by arrows; when visible vesicle wall was too thin to fit a double-sided arrow, horizontal arrow brackets were used and indicated in corresponding figure captions; adhesive brackets are white and flat ended. Dashed-line brackets indicate entirety of the structure is not visible in the frame of view.

acritarchs, including Shuiyousphaeridium macroreticulatum, Dictyosphaera delicata, Valeria lophostriata, and Tappania plana. This study focused on Dictyosphaera delicata and Shuiyousphaeridium macroreticulatum, the two most abundant species from the Shuiyougou acritarch assemblage. Although the method detailed here is highly applicable to (perhaps better-preserved) microfossils of younger geologic ages as well as modern microorganisms, acritarchs of this antiquity were specifically chosen because ultrastructures of conspecific and morphologically similar acritarchs have been documented using standard TEM techniques (Javaux et al., 2001, 2003, 2004). 
To extract acritarchs, $\sim 2$ grams of Shuiyougou carbonaceous shale was dissolved using standard hydrofluoric acid digestion techniques, and the resulting carbonaceous macerates were rinsed with distilled deionized water and then vacuum sieved with a $10 \mu \mathrm{m}$ nylon screen (Vidal, 1988). During inspection of the sieved macerates under stereomicroscopy, numerous individuals of Shuiyousphaeridium macroreticulatum and Dictyosphaera delicata were isolated, rinsed to remove any attached debris, placed on a glass slide, and photomicrographed. The specimens chosen for analysis ranged in color from orange-brown to brown and have a corresponding thermal alteration index (TAI) of 3-4, using the TAI scale published by Batten (1996) and consistent with the results reported by Marshall et al. (2005). Specifically selected were specimens that contained vesicularly enclosed central bodies, which have been interpreted as possible nuclear or other organelle remnants, as well as vestiges of degraded cytoplasm (Knoll and Barghoorn, 1975; Oehler, 1976, 1978; Golubic and Barghoorn, 1977; Hagadorn et al., 2006).

Following imaging under optical microscopy, the Shuiyougou shale specimens were prepared for FIB analysis. Circumventing such arduous sample preparation techniques as epoxy impregnation of the sample of interest, FIB-EM sample preparation is essentially identical to SEM sample preparation. The specimens were placed on a carbon- or coppertape mount on a standard-sized aluminum SEM stub. Removing a standard depth of material with each I-beam cross section may excavate into the mounting-tape medium, because acritarch vesicle thickness varies among specimens. Copper-tape mounts, therefore, were preferred to maximize compositional differences between the specimen and the mounting adhesive when viewed in cross section. After mounting the acritarchs, the aluminum stubs were gold-palladium sputter-coated to a thickness of $20 \mathrm{~nm}$ with a Cressington 208 HR (MTM-20 thicknesscontroller equipped) high-resolution sputter coater.

\section{FIB-EM Nanotomography}

Subsequent to Au-Pd sputter coating, the stubs were individually secured to the sample stage and inserted into the FIB-EM vacuum chamber. Once under vacuum, the I-beam and GIS warm-up sequences are initiated and the sample surface is scanned and navigated by the Ebeam. After a point of interest is determined and the LMIS source is ignited, the sample surface is adjusted to eucentric height where the Ebeam and I-beam are coincident, i.e., the region of interest on the sample is effectively the center of the sample chamber universe. I-beam imaging is inherently damaging to the sample but must be utilized to ensure that both beams are focused on the same point of the specimen; accordingly, several additional procedures during imaging are recommended to minimize marring the sample surface. First, lower I-beam currents may be used for imaging purposes, which allow for longer liveviewing times with minimal surficial damage; however, not only is the lower-current I-beam still destructive, the I-beam may also undergo a focal shift when increasing current, and thus the I-beam and E-beam may be slightly off coincident focus. Second, sequential I-beam snapshots may be used at higher currents to avoid refocusing the beam; but even with very short viewing times, this technique may result in significant surficial damage. Third, the organometallic platinum gas may be injected into the system without a deposition pattern in place; thus, when scanning the sample in I-beam mode (even at higher currents), a very thin layer of platinum is deposited, and the sample surface remains undamaged. This technique is probably the most efficient and commonly used. Finally, if the sample surface is relatively flat or there is a reasonably large surface area of the sample that is of lesser significance, the I-beam and E-beam can be brought to coincident focus outside of the region of interest.

After coincident focus is reached and the region of interest is determined, a deposition pattern is outlined. With the GIS, organometallic gas is injected into the vacuum chamber near the sample surface, and the I-beam is rastered throughout the deposition pattern, depositing the sacrificial platinum layer; other metals can be used, but platinum is the most common for sectioning purposes. Typically for FIB-EM preparation of TEM ultrathin foils, a small rectangular strip is used as the deposition pattern, and larger rectangular step-cutting patterns are positioned on both sides of this protective layer. After the protective layer is deposited, usually at a thickness of approximately $\leq 1 \mu \mathrm{m}$, the I-beam is rastered directly on the sample surface in both of the two cutting patterns to mill material away, leaving an undisturbed cross section. The entire cutting process can be concurrently monitored via E-beam imaging. Usually after completing the step-cuts, the sectioned surfaces are cleaned with the designated cleaning, or polishing, I-beam function (Fig. 2I).

For FIB-EM nanotomography, instead of depositing a protective strip, the entire region of interest should be covered with a thin, $<1 \mu \mathrm{m}$ layer of platinum (Figs. 2C-F). Again, a step-cutting pattern (Figs. 2C, I) is used at the leading edge of the platinum to allow for easy viewing of the cross sections. Unlike preparation of TEM foils, however, all subsequent ion-cutting patterns are simply very narrow strips, or cleaning-cross-section patterns. After each cut, the newly exposed section is imaged and the cutting pattern is advanced sequentially to obtain successive cross sections for the region of interest. The computer interface and concurrent E-beam imaging provide nanometer-scale positional accuracy for sequential cuts. A spatial resolution should be chosen that is appropriate for the features of interest. If nanometerscale features are of interest, these cutting strips may be as small as a single nanometer, but if imaging larger regions is desired, the cutting pattern can be lengthened to the micron scale. Using a trial and error approach, we achieved successful results using variable width, $3-5 \mu \mathrm{m}$ depth (z-axis; Fig. 2I) cleaning-cross-section patterns (Figs. 2C, I), which were advanced from $100 \mathrm{~nm}$ to $250 \mathrm{~nm}$ at a time, the most common thicknesses from the materials literature. To ensure that all of the leading edge material was cleanly and completely removed with each cleaning cross section, the patterns were generated at double the length (y-axis, Fig. 2I) of the advancement distance. For instance, a $200 \mathrm{~nm}$ y-axis length pattern was used for $100 \mathrm{~nm}$ length sections; this pattern would only be advanced $100 \mathrm{~nm}$ at a time for each sequential section and, therefore, had an extra $100 \mathrm{~nm}$ on the trailing edge that would not overlie any material of interest. Although sectioning patterns may be advanced $1 \mathrm{~nm}$ at a time, sequential sections of $<100 \mathrm{~nm}$ long can create surface amorphization complications. The shape of the ion beam is parabolic, and the wider upper portion of the beam can unevenly erode the platinum sacrificial layer above the uncut sample exterior. Increasing the number of tightly spaced sequential cross sections, therefore, results in a progressively thinner protective platinum layer, which eventually causes sample surface amorphization. The relatively large depth selection (z-axis) of our cross-sectioning patterns ensured that the entire thickness of the fossil, in addition to the $20 \mathrm{~nm}$ gold-palladium coating and the $\sim 1 \mu \mathrm{m}$ thick platinum sacrificial surface, was completely sectioned. As the volume of material excavated via the I-beam is directly proportional to the time of I-beam rastering, the selection of $100 \mathrm{~nm}$ or $250 \mathrm{~nm}$ cleaning section advancements was dependent on the total width (x-axis; Fig. 2I) of the sectioning pattern. For instance, in cases where the cutting pattern was narrow $(\leq 10 \mu \mathrm{m})$, $100 \mathrm{~nm}$ length sections were used for optimal spatial resolution, whereas $250 \mathrm{~nm}$ length sections were used for wider cross sections $(>10 \mu \mathrm{m})$ in an effort to maximize both spatial resolution and time efficiency for three-dimensionally analyzing and reconstructing up to nearly $20 \mu \mathrm{m}$ of the fossils.

The sequential electron images were first thresholded in Adobe Photoshop ${ }^{\circledR}$ CS2 to black and white binary representations, in order to extract only the pixels corresponding to the sectioned microfossil material (Figs. 2G-H). This alteration removes any unwanted image data, such as sections of the mounting tape and platinum protective layer. Additionally, because the sample is tilted $52^{\circ}$ below horizontal in 
order to establish perpendicularity to the I-beam, the SEM micrographs of the ion sections are oriented $142^{\circ}$ (rather than perpendicular) to the surface of the sample to obtain the best available view of the cross section. The resultant image data, therefore, inherently contains a yaxis length component (Fig. $2 \mathrm{G}$ ), and the thresholding procedure is a necessary step to reduce the three-dimensionality of the microfossil image to only two dimensions (Fig. 2H). These 2-D binary images are then organized into image stacks, and then imported into Kitware, Inc. ParaView 2.6.2 software for three-dimensional rendering. ParaView uses a marching cubes algorithm, which extracts a polygonal mesh of an isosurface - a surface that represents points of a constant value, in this case composition of the microfossils - from the two-dimensional image stacks. The individual polygons are then incorporated into 3-D surface renderings of the structures of interest. Furthermore, these surface models can be converted to $3-\mathrm{D}$ volume renderings by reducing the opacity of the surface contours, which helps to elucidate internally contained structures - an important feature for analyzing complex microfossil ultrastructures.

\section{RESULTS}

\section{Light and Scanning Electron Microscopy}

Light and electron microscopy confirm previously published data (Xiao et al., 1997; Javaux et al., 2004), and the results are described briefly here. The vesicles of Dictyosphaera delicata and Shuiyousphaeridium macroreticulatum are 50-300 $\mu \mathrm{m}$ in diameter (Figs. 3F, 4A). Vesicle walls consisting of interlocking polygonal (mostly hexagonal) plates characterize both taxa; although $D$. delicata is herkomorphic and lacks processes (spines), whereas S. macroreticulatum is acanthomorphic with unevenly distributed extravesicular processes. The hexagonal plates are 1.5-3 $\mu \mathrm{m}$ in maximum width, and the plate boundaries correspond to raised ridges on the outer vesicle walls. The raised ridges are 100-300 nm thick and 100-200 nm high. True excystment structures are unknown (Xiao et al., 1997). The processes on $S$. macroreticulatum are flared typically or conspicuously branched and are on average 10-15 $\mu \mathrm{m}$ long and 2-3 $\mu \mathrm{m}$ in diameter. The processes have been described as hollow and appear to be open at the distal end and flare outward at both the vesicular attachment point and tip, although SEM imaging indicates that some of the processes have rounded or bulbous terminations. In addition, a discontinuous outer membrane, supported by the processes, appears to be present in some specimens. Furthermore, some vesicles of $D$. delicata and $S$. macroreticulatum contain circular opaque internal bodies, which are clearly seen under transmitted light microscopy (Fig. 4A).

\section{FIB-EM Nanotomography of Dictyosphaera delicata}

In an effort to refine the FIB sequential ion section technique, a total of 10 Dictyosphaera delicata specimens were used as test subjects. From these specimens, numerous FIB ultra-thin sections were constructed (Figs. 3AE) to establish a 2-D baseline for ultrastructures observed using the sequential ion sectioning technique. A total of 90 cross sections were made at a spacing of $100 \mathrm{~nm}$, covering a distance of approximately $9 \mu \mathrm{m}$. These sections were $8.2 \mu \mathrm{m}$ wide. The ultrastructures of $D$. delicata vesicles are relatively simple. Vesicle walls vary in thickness, but are typically constrained between approximately 200 to $500 \mathrm{~nm}$. The vesicle walls are multilamellar (Figs. 3A-E, H-I), similar to the multilayered vesicle walls of Shuiyousphaeridium macroreticulatum as reported in TEM ultrastructural analyses (see figs. 5H-J in Javaux et al., 2004). The innermost layer, which shows up in a lighter grayscale with both the ETD and TLD, is approximately $150 \mathrm{~nm}$ thick where visible. With sequential ion sectioning, it was observed that the two vesicle walls contain smaller chambers (maximum diameters from 460 to $548 \mathrm{~nm}$ ) distinct from the large vesicle cavity (Fig. 3K). Moreover, the vesicle walls merge and separate multiple times (Figs. 3H-J).

\section{FIB-EM Nanotomography of Shuiyousphaeridium macroreticulatum}

After the nanotomography technique had been refined with Dictyosphaera specimens, more complex vesicles of Shuiyousphaeridium macroreticulatum were prepared and analyzed. Two features were of primary interest with these acanthomorphic acritarchs for use of FIB nanotomography: the 3-D ultrastructures of processes and central bodies. After observation under standard optical microscopy, six specimens with readily identifiable central bodies were prepared for and analyzed via the FIB nanotomographic technique. Under ion imaging, these specimens showed topographically raised regions on the vesicle wall that correspond to the location of the central bodies (Fig. 4C). Convenient for our ultrastructural goals, in one specimen, what we interpreted as an extravesicular process was also situated on the outer vesicle wall at the edge of the central body (Figs. 4B-C). A total of 70 cross sections with $250 \mathrm{~nm}$ spacing and $15.4 \mu \mathrm{m}$ widths were conducted in this specimen, occupying a total distance of $17.25 \mu \mathrm{m}$. The nanotomography of this specimen serves as the focal case study for both the central body and extravesicular process, which are described below.

Central body ultrastructure.-As was expected from the topographic observation with ion imaging, sequential-ion sectioning moving into the vesicularly enclosed central body was accompanied by an overall thickening of the fossil, from a relatively consistent total vesicle thickness of 300-500 nm-individual vesicle wall thickness ranging from $\sim 150 \mathrm{~nm}$ to $\sim 250 \mathrm{~nm}$ - to a total thickness of approximately $1500 \mathrm{~nm}$. Throughout the analyzed region of the central body, there is no distinction between the vesicle walls and the central body, i.e., no gaps exist between the central body and the vesicle walls. Given that the vesicle walls of compressed acritarchs can merge (Figs. $3 \mathrm{H}-\mathrm{J}$ ), it is possible that the compressed vesicle wall and central body can merge during diagenesis as well. No direct measurement, thus, could be made on the thickness of the central body, but it is estimated to be $1000 \mathrm{~nm}$ by assuming vesicle wall thicknesses of $250 \mathrm{~nm}$, the maximum measured individual wall thickness outside of the central body region. In addition to the overall thickening of the acritarch, the central body is distinguished by a high incidence of nanometer-scale pores. These nanopores show an order of magnitude in size range, from $5.8 \mathrm{~nm}$ at smallest to $58.2 \mathrm{~nm}$ at largest (Figs. 4D-F). We localized the pores to the central-body region by adding a hypothetical vesicle wall, using $250 \mathrm{~nm}$ as individual wall thicknesses to these image slices (Figs. 4DE). At any given image slice of the central body, up to 25 nanopores can be identified in an area of $5120 \mathrm{~nm}$ (field of view width at 25,000X magnification) $\times 1000 \mathrm{~nm}$ (total estimated central body thickness) (Figs. 4D-E). In one isolated case, one of the larger nanopores shows a tangential extension downward toward the stub mount. This extension covers a length of $575.7 \mathrm{~nm}$, nearly ten times the diameter of the nanopore (Fig. 4F), suggesting that this nanopore may be a cylindrical nanotube.

Process ultrastructure.-The structure interpreted as an extravesicular process examined via FIB-EM nanotomography was located on the vesicle surface, near the outer boundary of the raised central body region (Figs. 4A-C, and B inset). With the site-specificity capabilities of the FIB-EM system, we were able to section laterally through the length of this structure (see Figs. 4G-J, 5A-J). A total length of approximately $4.5 \mu \mathrm{m}$ of the process was cross sectioned (19 total sections), illustrating a complex structure with multiple chambers rather than a simple hollow or cylindrical process. Moreover, through the $4.5 \mu \mathrm{m}$ of sectioning, images of two distinct, but conjoined structures were captured: a larger bulbous structure with a maximum diameter of $3.23 \mu \mathrm{m}$ and $\sim 3.00 \mu \mathrm{m}$ long, occupying a total of 13 sections (Figs. 5A-H), and a smaller stalklike columnar structure with a maximum diameter of $1.51 \mu \mathrm{m}$ and $\sim 3.50 \mu \mathrm{m}$ long, occupying a total of 15 sections (Figs. $5 \mathrm{C}-\mathrm{J}$ ). The 

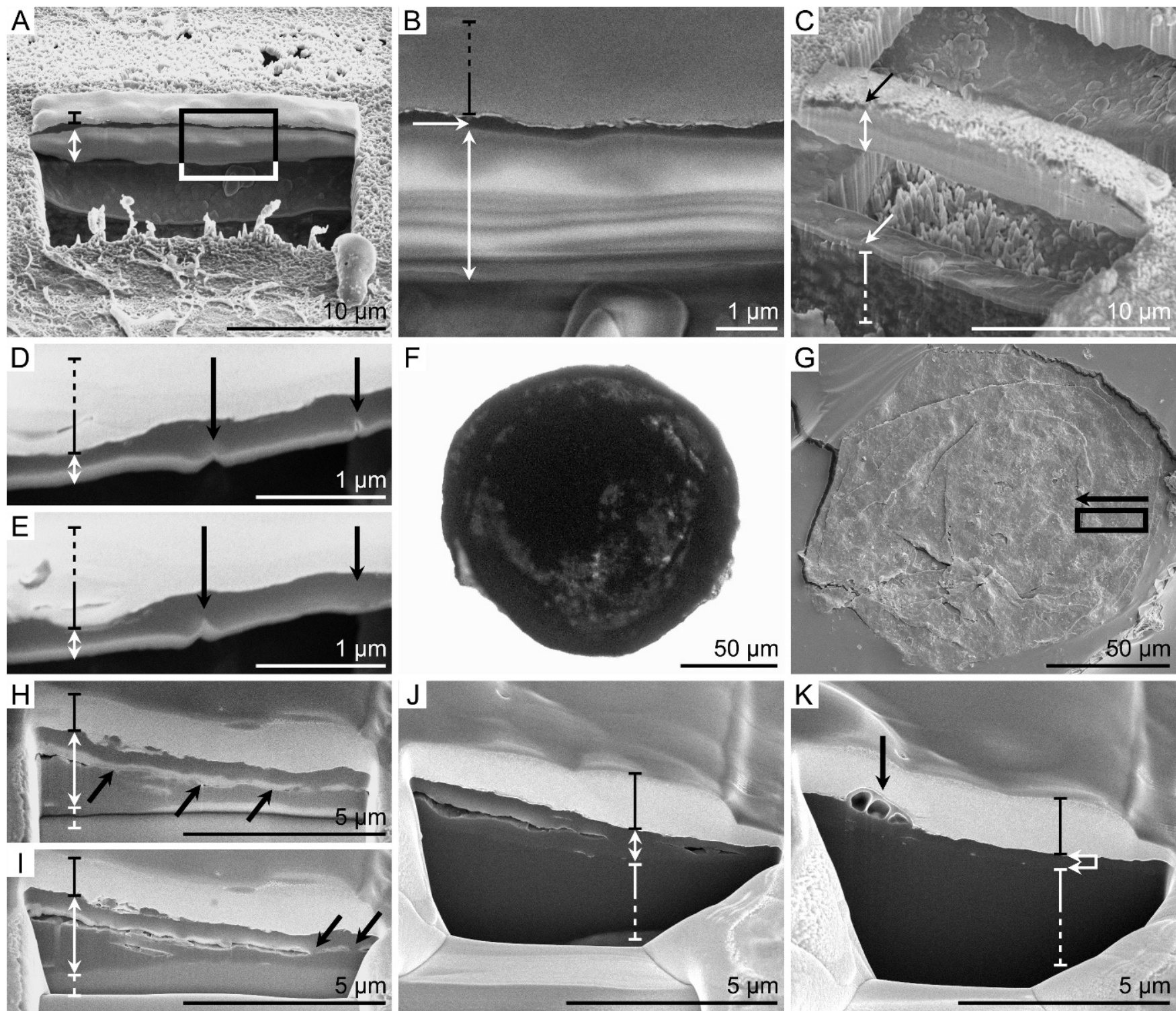

FIGURE 3-Electron and light micrographs of Dictyosphaera delicata specimens, focusing on vesicle wall ultrastructures. A-E) Baseline vesicle wall ultrastructures; F-K) single FIB nanotomography-prepared $D$. delicata specimen; A) Step-cut cross-sectional view. B) Higher magnification of boxed area in (A), of multilamellar vesicle wall, horizontal white arrow illustrates $20 \mathrm{~nm}$ thick Au-Pd sputter coating. C) Dual step-cut (TEM-ultrathin section preparation) cross-sectional view of multilamellar vesicle wall, black arrow indicates edge of protective Pt strip, lower white arrow indicates edge of lower vesicle wall edge. D) Cross-sectional view of multilamellar vesicle wall and inner incisions (arrows) correspond to polygonal plate boundaries. E) Sequential cross section (SCS, $100 \mathrm{~nm}$ y-length from D) of migration (left arrows in D-E) and termination (right arrows in $\mathrm{D}$ and $\mathrm{E}$ ) of inner incisions due to oblique sectioning through polygonal fields. F) Light micrograph of $D$. delicata specimen, with FIB-EM images shown in (GK). G) Electron micrograph of Pt deposition pattern (box) and direction (arrow) of sequential FIB cross sections; overall morphology was slightly damaged during transfer to SEM stub. H) Initial step-cut cross section showing multilamellar ultrastructure of both vesicle walls; arrows indicate vesicle wall conjunction, although vesicle walls are merged through most of the cross section. I) SCS $(100 \mathrm{~nm}$ from $\mathrm{H})$ of larger spacing between vesicle walls, and slight convergences of vesicle walls and disappearance of multilamellar ultrastructure (arrows). J) SCS (3100 nm from I ) of mostly merged vesicle walls. K) SCS (1800 nm from J) with three chambers (arrow) on outer edge of vesicle wall, horizontal white arrow bracket illustrates vesicle thickness.

larger bulbous structure has a rounded central vacuole, with a maximum diameter of $1494 \mathrm{~nm}$, and up to 8 smaller, radially adjacent, elliptical to reniform chambers (maximum dimension $=1255 \mathrm{~nm}$ ). These reniform chambers are laterally extensive, continuing proximally to distally and perpendicular to the plane of the cross sections. The smaller columnar structure, flanking and briefly contiguous to the larger bulbous structure, does not show the same chamber arrangement. Rather, it consists of a maximum of four axially arranged, predominantly elliptical, and laterally intermittent chambers (maximum dimension $=539 \mathrm{~nm}$ ) that disappear and reappear suddenly without tapering through the sequential sectioning. The bulbous and columnar structures are conjoined briefly: the columnar structure first joins with the bulbous structure prior to its midpoint, at only
$1.00 \mu \mathrm{m}$ into the structure, and continues for an additional $1.50 \mu \mathrm{m}$ past the end of the bulbous structure. Both of these structures maintain attachment to the outer vesicle surface for nearly their entire lengths but show no evidence of communication with the vesicle cavity. Furthermore, a shroud of organic material covers this complex set of structures through nearly the entire sectioning length (Figs. 5D-J). This shroud is attached to the bulbous structure at approximately its midpoint, coincident with the start of the columnar structure, and it covers the majority of the smaller columnar structure. Three-dimensional models of these structures, both as a surface rendering and a volume rendering with highlighted continuous chamber space, are shown in Figures $5 \mathrm{~K}-\mathrm{N}$ (data from 29 cross sections included, representing $7.0 \mu \mathrm{m}$ of material). Conceptual 

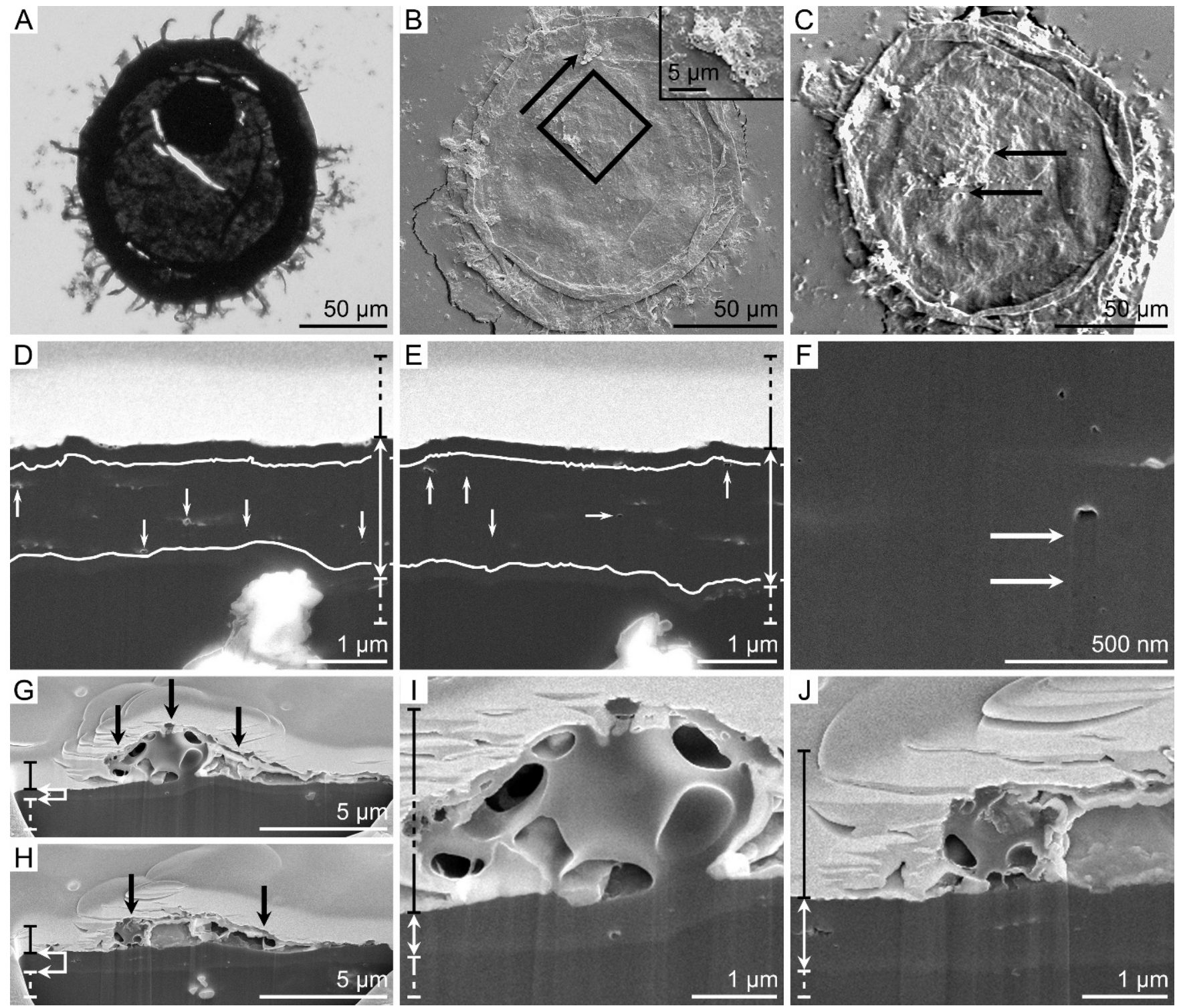

FIGURE 4-Representative light, electron, and ion micrographs of single FIB nanotomography-prepared Shuiyousphaeridium macroreticulatum specimen, showing central body, process, and outer membrane ultrastructures. A) Light micrograph of S. macroreticulatum specimen with FIB-EM images shown in (B-J). B) Electron micrograph of Pt deposition pattern (box) and direction (arrow) of sequential cross sections, inset electron micrograph shows higher magnification of sectioned surficial process (cross sections in G-J). C) Ion micrograph (rotated $\sim 45^{\circ}$ counterclockwise from B) showing central body (upper arrow, cross sections in D-F) and surficial process (lower arrow). D) Numerous nanopores (arrows) in central body, white lines show hypothetical vesicle wall thickness of $250 \mathrm{~nm}$. E) Sequential cross section (750 nm y-length from D) of continuance of nanopores (arrows) through central body; white lines show hypothetical vesicle wall thicknesses of $250 \mathrm{~nm}$. F) High magnification view of nanopore with tangential extension (horizontal arrow in E) indicated by arrows. G) Cross-sectional view of bulbous tip of process (central black arrow), stalk (left black arrow), and organic membrane shroud (right black arrow); horizontal white arrow brackets indicate vesicle wall thickness (binary data shown in Fig. 5E). H) Cross-sectional view of process stalk (left black arrow) and organic membrane shroud (right black arrow); horizontal white arrow brackets indicate vesicle wall thickness. I) Higher magnification view of (G), showing multiple radial chambers (but no central vacuole) and beginning of columnar stalk to the left. J) Higher magnification view of (H), showing four axially arranged circular to elliptical chambers.

diagrams of the full living view of a $S$. macroreticulatum vesicle, as well as tentative reconstructions of the process structure both in life and as sectioned from the fossil representative are shown in Figure 6. While these diagrams are admittedly speculative, they incorporate key characteristics observed both in previously examined specimens as well as information elucidated via the FIB-EM nanotomographic method and, therefore, provide the most comprehensive interpretation possible from the available surficial and ultrastructural data.

\section{DISCUSSION}

FIB nanotomography of the Ruyang Group specimens shown here illustrate numerous similarities to previously published ultrastructures detailed from TEM examination of conspecific and morphologically similar Roper Group acritarchs, such as multilayered vesicle walls comprised of reticulate organic plates (Javaux et al., 2001, 2003, 2004). Such similarities to data observed with more extensively tested techniques illustrate the viability of FIB nanotomography as a method for examining microfossil ultrastructures.

The biological origin of the chambers within the vesicle walls of Dictyosphaera delicata (Fig. 3K) is debatable, as they may be products of taphonomic or thermal alteration, similar to the amalgamation and separation of compressed vesicle walls in the same specimens (Figs. 3H-J). Nonetheless, it is important to note that similar chambers, described as rounded voids - maximum diameter of approximately $3 \mu \mathrm{m}$, nearly an order of magnitude larger than those observed here-have been observed from TEM ultrastructural examination of younger (ca. $580 \mathrm{Ma}$ ) and less thermally mature $(\mathrm{TAI}=2-3$, Willman 


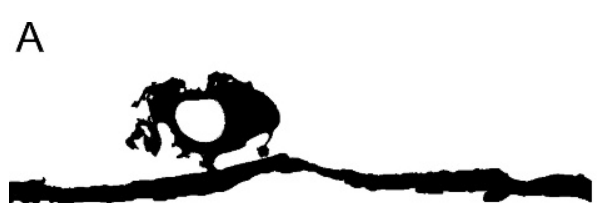

F

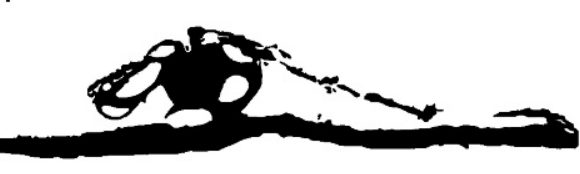

B

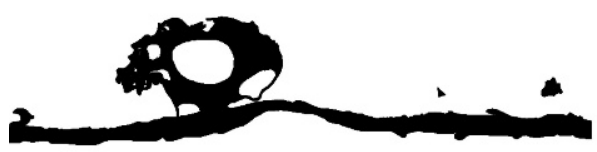

G

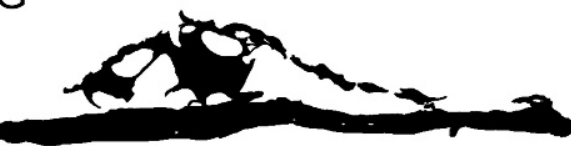

C

$\mathrm{H}$
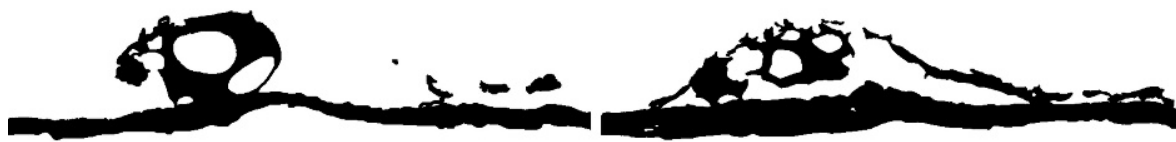

I
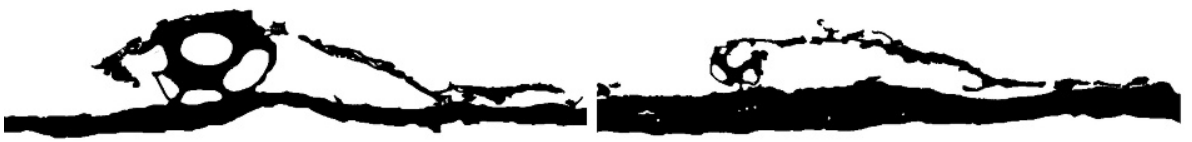

E

$\mathrm{J}$
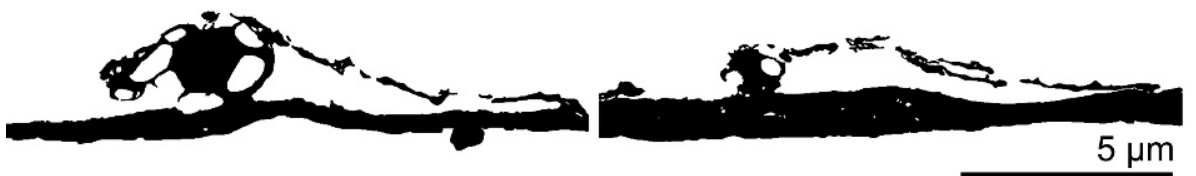

$\mathrm{K}$
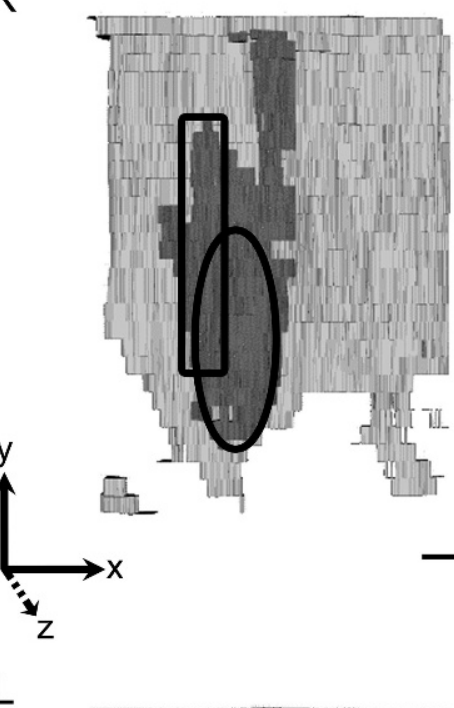

$5 \mu \mathrm{m}$

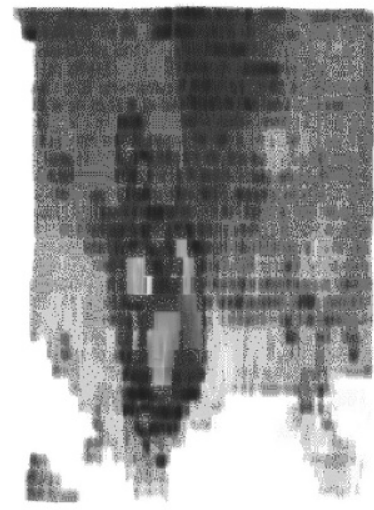

$5 \mu \mathrm{m}$

FIGURE 5-Cross-sectional binary data (BD) and 3-D renderings (3D-R) of Shuiyousphaeridium macroreticulatum specimen shown in Figure 4. A-J) BD from FIB nanotomography-prepared S. macroreticulatum specimen; K-N) 3D-R from FIB nanotomography of specimen in Figure 4. Y-axis length exaggerated $\sim 3: 1$ for clarity; scale bars accurate for $\mathrm{x}$-width and z-depth measurements. A) BD of bulbous process termination (bulb) showing large central vacuole (LCV) and one unclosed radial chamber (RC) on lower right. B) BD (250 nm y-length from A) of bulb with LCV, five small RCs, and hints of outer membrane shroud (OMS) on right. C) BD (250 nm from B) of bulb with LCV, large elliptical RC on lower right of LCV, and semblance of OMS on right. D) BD (250 nm from C) of bulb showing LCV, three elliptical RCs on lower edge of LCV, and more continuous OMS. E) BD (250 nm from D) of bulb with no LCV, six large elliptical RCs (two unclosed RCs on lower left), continuous OMS, and columnar stalk portion of process (stalk) at left edge of bulb. F) BD (250 nm from E) of bulb showing no LCV, seven large elliptical RCs (two unclosed RCs on lower left), mostly continuous OMS, and stalk at left edge of bulb. G) BD ( $250 \mathrm{~nm}$ from F) of bulb edge with no LCV, five disorganized RCs (two unclosed RCs on lower left), four smaller RCs in upper bulb, one smaller RC at bulb base, mostly continuous OMS, and more defined stalk at left edge of bulb. H) BD (250 nm from G) of bulb edge detached from vesicle wall, mostly continuous OMS, and tenuous connection of stalk to outer vesicle surface. I) BD (750 nm from H) with no bulb visible, mostly continuous OMS, and stalk with four RCs. J) BD (250 nm from I) with mostly continuous OMS and stalk with two outer edge RCs. K) Top view surface 3D-R, with darker region representing bulb (ellipse), stalk (rectangle), and part of the OMS (axes applicable for K and L). L) Top view of volume 3D-R, white inclusions represent continuous RCs or LCV within process (unclosed RCs not included).

et al., 2006) leiosphere acritarchs from the Officer Basin, South Australia (Willman, 2009). Likely in much the same conundrum as ours, however, neither a biological nor a taphonomic interpretation has been offered for the voids in leiosphere walls (Willman, 2009). FIB nanotomography of Shuiyousphaeridium specimens, on the other hand, illustrated complexities unknown from previous examination. First, the nanoporous structures present in the central bodies may represent nanotubular structures of biological significance. These structures are intriguingly similar to nanoporous structures observed on the vesicle walls of Dictyosphaera delicata (see figs. 1D, F of Kaufman and Xiao, 2003), but those observed here are restricted to the central body region and show no evidence of continuing through the outer vesicle walls. There is a great deal of missing data by removing $250 \mathrm{~nm}$ of material between cross sections, however, because the size range of these structures is so small. It is difficult to determine, therefore, whether these nanopores are a network of interconnected nanotubes. In an effort to resolve this problem, we are currently adapting the nanotomography method to remove much less material $(10 \mathrm{~nm})$ between sequential ion sections, but this presents the problem of surface amorphization described earlier in the Methods section. The two interconnected, process-like structures, if they are indeed part of what is commonly recognized as an external process, are far more intricate than hollow cylindrical processes as previously described from these fossils (Xiao et al., 1997). Their relatively consistent fusion with the vesicle wall may draw the process interpretation into question, but this connection throughout nearly the entire length of the process is likely taphonomic, similar to the amalgamation of compressed vesicle walls in $D$. delicata. As is observable in our conceptualized representation of these structures (Fig. 6), we interpret the larger bulbous structure as the process termination attached to the vesicle surface by the stalklike columnar structure. While most processes observed on $S$. macroreticulatum in both light and electron microscopy show flared or branched terminations, bulbous structures have been observed on numerous specimens - although rare. We do not feel that the bulbous process termination is the common form, though it may be more frequent than observed if it is easily damaged or ripped from the 


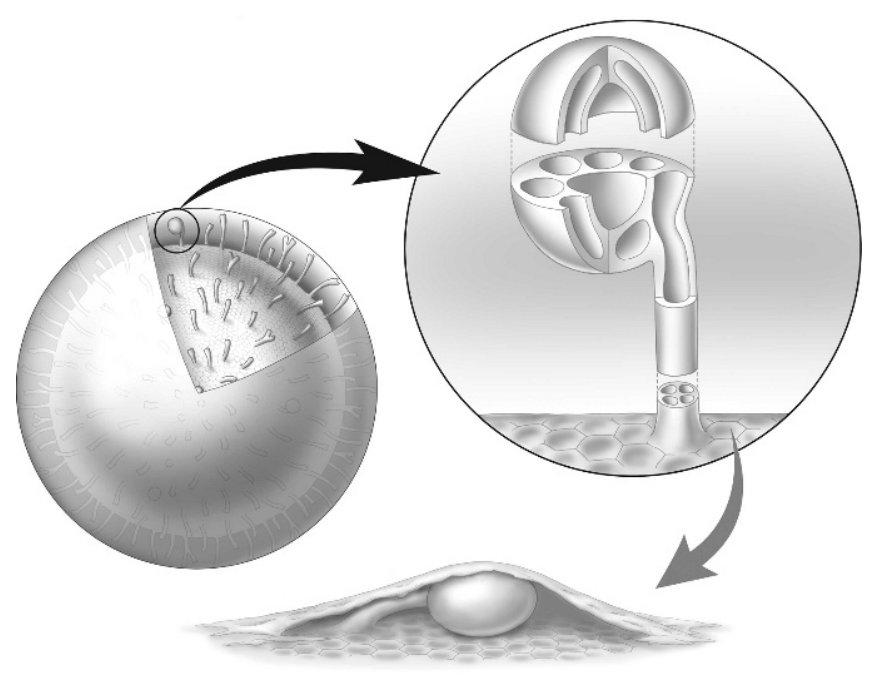

FIGURE 6-Conceptualization of process ultrastructure and fossil observations. Left illustration shows living full vesicle depiction with outer membrane, upper slice removed to show process distribution, morphologies, and vesicle surface reticulation; right illustration (following black arrow) shows higher magnification view and hypothetical structural and ultrastructural representation of bulbous-tipped process as it may have appeared during the life of the acritarch; lower illustration (following grey arrow) shows conceptual reconstruction of fossil bulbous-tipped process and outer membrane shroud as sectioned during FIB-EM analyses.

processes during maceration and handling. Another feature of note is the shroud of organic material that covers the majority of the processlike structure. We suggest that this shroud potentially represents a fragment of an outer membrane, which has previously been described as a thin organic veil supported by the extravesicular processes (Xiao et al., 1997). The surficial feature observed under electron imaging, therefore, likely reflects this shroud rather than the extravesicular process observed in FIB nanotomography. The process is obscured underneath and thus protected by the outer membrane shroud. Further, one apparent detail that can be resolved from the process ultrastructural reconstruction is the lack of communication between the process - specifically the stalk in our conceptualized view-and the inner vesicle cavity. As a final point, the segmented chambers viewed in the smaller columnar structure and the vacuolated larger bulbous structure illustrate a level of ultrastructural complexity that was not previously documented in Ruyang Group acritarchs and, therefore, should compel further microfossil ultrastructural study via FIB-EM nanotomography.

\section{CONCLUSIONS}

In summary, we have illustrated that the FIB-EM technique presents opportunities to examine the three-dimensionality and continuity of microfossil ultrastructures with numerous advantages over standard SEM and TEM techniques. As simply a TEM ultrathin foil preparation tool, FIB-EM workstations offer considerable benefits - predominantly its site-specificity—over standard ultramicrotomy and electropolishing techniques. Perhaps more importantly, as this technique provides a 3-D element to the study of microfossil ultrastructures, requires little sample preparation, and introduces few artifacts, the study of microfossils stands much to gain by popularizing the use of FIB nanotomography. An interesting prospect of this 3-D ultrastructural technique is to combine with analyses from other such advanced instruments as microFourier transform infrared (FTIR) spectroscopy (e.g., Marshall et al., 2005), for integrated ultrastructural and chemical investigation, which could potentially shed light on taxonomic affinities of problematic microfossils. Further studies that would jointly consider possible modern analogs of acritarchs, such as dinoflagellate cysts and diapause animal eggs, would undoubtedly aid in unlocking some of the taxonomic puzzles surrounding acritarch interpretations.

\section{ACKNOWLEDGMENTS}

The research was supported by NASA Exobiology and Evolutionary Biology Program, the Virginia Tech Institute for Critical Technology and Applied Science (ICTAS), and the Virginia Space Grant Consortium. Analyses were conducted at the Virginia Tech ICTAS Nanoscale Characterization and Fabrication Laboratory, with technical help from S.R.F. McCartney and J. McIntosh. 3-D renderings were constructed with the assistance of P. Shinpaugh (VT-CAVE, Visualization and Animation Group of ICTAS); and J. Norton provided conceptual graphical representations of the Shuiyousphaeridium macroreticulatum process. We additionally thank T.A. Dexter, PALAIOS coeditor S. T. Hasiotis, associate editor B. Granier, and two anonymous reviewers for critical comments that greatly improved the quality of this report.

\section{REFERENCES}

Arouri, K.R., Greenwood, P.F., and Walter, M.R., 1999, A possible chlorophycean affinity of some Neoproterozoic acritarchs: Organic Geochemistry, v. 30, p. $1323-1337$.

Arouri, K.R., Greenwood, P.F., and Walter, M.R., 2000, Biological affinities of Neoproterozoic acritarchs from Australia: Microscopic and chemical characterisation: Organic Geochemistry, v. 31, p. 75-89.

BARBER, D.J., 1970, Thin foils of non-metals made for electron microscopy by sputteretching: Journal of Materials Science, v. 5, p. 1-8.

BARBER, D.J., 1999, Development of ion-beam milling as a major tool for electron microscopy: Microscopy and Analysis, v. 36, p. 5-8.

Batten, D.J., 1996, Palynofacies and petroleum potential, in Jansonius, J., and McGregor, D.C., eds., Palynology: Principles and Applications: American Association of Stratigraphic Palynologists Foundation, College Station, Texas, p. 1065-1084.

Benzerara, K., Menguy, N., Guyot, F., Vanni, C., and Gillet, P., 2005, TEM study of a silicate-carbonate-microbe interface prepared by focused ion beam milling: Geochimica et Cosmochimica Acta, v. 69, p. 1413-1422.

Bernard, S., Benzerara, K., Beyssac, O., Menguy, N., Guyot, F., Brown Jr., G.E., and Goffé, B., 2007, Exceptional preservation of fossil plant spores in highpressure metamorphic rocks: Earth and Planetary Science Letters, v. 262, p. 257272.

Castaing, R., and Labourie, P., 1953, Examen direct des métaux par transmission au microscope électronique: Comptes Rendus Académie des Sciences, v. 237, p. 1330 1332 .

Cavalazzi, B., 2007, Chemotrophic filamentous microfossils from the Hollard Mound (Devonian, Morocco) as investigated by focused ion beam: Astrobiology, v. 7, p. 402-415.

Cohen, P.A., Knoll, A.H., and Kodner, R.B., 2009, Large spinose microfossils in Ediacaran rocks as resting stages of early animals: Proceedings of the National Academy of Sciences USA, v. 106, p. 6519-6524.

EvitT, W.R., 1963, A discussion and proposals concerning fossil dinoflagellates, hystrichospheres, and acritarchs: Proceedings of the National Academy of Sciences, USA, v. 49, p. 158-164, 298-302.

Floss, C., Stadermann, F.J., Bradley, J., Dai, Z.R., Bajt, S., and Graham, G., 2004, Carbon and nitrogen isotopic anomalies in an anhydrous interplanetary dust particle: Science, v. 303, p. 1355-1358.

Giannuzzi, L.A., Prenitzer, B.I., Drown-MacDonald, J.L., Brown, S.R., Irwin, R.B., Stevie, F.A., and Shofner, T.L., 1998, Advances in the FIB lift-out technique for TEM specimen preparation: HREM lattice imaging Microstructural Science, v. 26, p. 249-253.

Giannuzzi, L.A., Prenitzer, B.I., Drown-MacDonald, J.L., Shofner, T.L., Brown, S.R., IRwIN, R.B., and STEVIE, F.A., 1999, Electron microscopy sample preparation for the biological and physical sciences using focused ion beams: Journal of Process Analytical Chemistry, v. 4, p. 162-167.

Golubic, S., and Barghoorn, E.S., 1977, Interpretation of microbial fossils with special reference to the Precambrian, in Flügel, E., ed., Fossil Algae: Recent Results and Developments: Springer-Verlag, Berlin, p. 1-14.

Groeber, M.A., Haley, B.K., Uchic, M.D., Dimiduk, D.M., and Ghosh, S., 2006, $3 \mathrm{D}$ reconstruction and characterization of polycrystalline microstructures using a FIB-SEM system: Materials Characterization, v. 57, p. 259-273. 
Hagadorn, J.W., Xiao, S., Donoghue, P.C.J., Bengtson, S., Gostling, N.J., Pawlowska, M., Raff, E.C., Raff, R.A., Turner, F.R., Yin, C., Zhou, C., Yuan, X., McFeely, M.B., Stampanoni, M., and Nealson, K.H., 2006, Cellular and subcellular structure of Neoproterozoic embryos: Science, v. 314, p. 291-294.

Han, T.-M., and Runnegar, B., 1992, Megascopic eukaryotic algae from the 2.1 billion-year-old Negaunee Iron-Formation, Michigan: Science, v. 257, p. 232-235.

Heaney, P.J., Vicenzi, E.P., Giannuzzi, L.A., and Livi, K.J.T., 2001, Focused ion beam milling: A method of site-specific sample extraction for microanalysis of Earth and planetary materials: American Mineralogist, v. 86, p. 1094-1099.

Holzer, L., Gasser, P., Kaech, A., Wegmann, M., ZingG, A., Wepf, A., and Münch, B., 2007, Cryo-FIB-nanotomography for quantitative analysis of particle structures in cement suspensions: Journal of Microscopy, v. 227, p. 216-228.

Holzer, L., Indutnyi, F., Gasser, P., Münch, B., and Wegmann, M., 2004, Threedimensional analysis of porous $\mathrm{BaTiO} 3$ ceramics using FIB nanotomography: Journal of Microscopy, v. 216, p. 84-95.

Holzer, L., Münch, B., Wegmann, M., Gasser, P., and Flatt, R.J., 2006, FIBnanotomography of particulate systems - Part I: Particle shape and topology of interfaces: Journal of the American Ceramic Society, v. 89, p. 2577-2585.

Inkson, B.J., Mulvihill, M., and MöBus, G., 2001, 3D determination of grain shape in a FeAl-based nanocomposite by 3D FIB tomography: Scripta Materialia, v. 45, p. $753-758$.

Javaux, E.J., Knoll, A.H., and Walter, M.R., 2001, Morphological and ecological complexity in early eukaryotic ecosystems: Nature, v. 412, p. 66-69.

Javaux, E.J., Knoll, A.H., and Walter, M.R., 2003, Recognizing and interpreting the fossils of early eukaryotes: Origins of Life and Evolution of the Biosphere, $\mathrm{v}$ 33, p. 75-94.

JavauX, E.J., Knoll, A.H., and Walter, M.R., 2004, TEM evidence for eukaryotic diversity in mid-Proterozoic oceans: Geobiology, v. 2, p. 121-132.

JavauX, E.J., and Marshal, C.P., 2006, A new approach in deciphering early protist paleobiology and evolution: Combined microscopy and microchemistry of single Proterozoic acritarchs: Review of Palaeobotany and Palynology, v. 139, p. 1-15.

Kaufman, A.J., and Xiao, S., 2003, High $\mathrm{CO}_{2}$ levels in the Proterozoic atmosphere estimated from analyses of individual microfossils: Nature, v. 425, p. 279-282.

Kempe, A., Wirth, R., Altermann, W., Stark, R.W., Schopf, J.W., and Heckl, W.M., 2005, Focused ion beam preparation and in situ nanoscopic study of Precambrian acritarchs: Precambrian Research, v. 140, p. 36-54.

Knoll, A.H., and Barghoorn, E.S., 1975, Precambrian eukaryotic organisms: A reassessment of the evidence: Science, v. 190, p. 52-54.

Kubis, A.J., Shiflet, G.J., Dunn, D.N., and Hull, R., 2004, Focused ion-beam tomography: Metallurgical and Materials Transactions A, v. 35A, p. 1935-1943.

Lee, M.R., Bland, P.A., and Graham, G., 2003, Preparation of TEM samples by focused ion beam (FIB) techniques: Applications to the study of clays and phyllosilicates in meteorites: Mineralogical Magazine, v. 67, p. 581-592.

Luo, Q., Zhang, Y., and Sun, S., 1985, The eukaryotes in the basal Changcheng System of Yanshan Ranges: Acta Geologica Sinica, v. 1985, p. 12-16.

Marko, M., Hsieh, C., Schalek, R., Frank, J., and Mannella, C., 2007, Focusedion-beam thinning of frozen-hydrated biological specimens for cryoelectron microscopy: Nature Methods, v. 4, p. 215-217.

Marshall, C.P., JavauX, E.J., Knoll, A.H., and Walter, M.R., 2005, Combined micro-Fourier transform infrared (FTIR) spectroscopy and micro-Raman spectroscopy of Proterozoic acritarchs: A new approach to Palaeobiology: Precambrian Research, v. 138, p. 208-224.

Meng, F., Zhou, C., Yin, L., Chen, Z., and Yuan, X., 2005, The oldest known dinoflagellates: Morphological and molecular evidence from Mesoproterozoic rocks at Yongji, Shanxi Province: Chinese Science Bulletin, v. 50, p. 1230-1234.

Moldowan, J.M., and Talyzina, N.M., 1998, Biogeochemical evidence for dinoflagellate ancestors in the Early Cambrian: Science, v. 281, p. 1168-1170.

OeHLER, D.Z., 1976, Transmission electron microscopy of organic microfossils from the late Precambrian Bitter Springs Formation of Australia: Techniques and survey of preserved ultrastructure: Journal of Paleontology, v. 50, p. 90-106.

Oehler, D.Z., 1978, Pyrenoid-like structures in late Precambrian algae from the Bitter Springs Formation of Australia: Journal of Paleontology, v. 51, p. 885-901.

Prenitzer, B.I., Urbanik-Shannon, C.A., Giannuzzi, L.A., Brown, S.R., and Irwin, R.B., 2003, The correlation between ion beam/material interactions and practical FIB specimen preparation: Microscopy and Microanalysis, v. 9, p. 216-231.

Rubanov, S., and Munroe, P.R., 2004, FIB-induced damage in silicon: Journal of Microscopy, v. 214, p. 213-221.
Schiffbauer, J.D., Yin, L., Bodnar, R.J., Kaufman, A.J., Meng, F., Hu, J., Shen, B., Yuan, X., Bao, H., and Xiao, S., 2007, Ultrastructural and geochemical characterization of Archean-Paleoproterozoic graphite particles: Implications for recognizing traces of life in highly metamorphosed rocks: Astrobiology, v. 7, p. $684-704$.

Schopf, J.W., 1992, Proterozoic prokaryotes: Affinities, geologic distribution, and evolutionary trends, in Schopf, J.W., and Klein, C., eds., The Proterozoic biosphere: A multidisciplinary study: Cambridge University Press, Cambridge, United Kingdom, p. 195-218.

Schopf, J.W., and Oehler, D.Z., 1976, How old are the eukaryotes?: Science, v. 193, p. $47-49$.

Schulz, H.N., Brinkhoff, T., Ferdelman, T.G., Mariné, M.H., Teske, A., and JørGENSEN, B.B., 1999, Dense populations of a giant sulfur bacterium in Namibian shelf sediments: Science, v. 284, p. 493-495.

Servais, T., 1996, Some considerations on acritarch classification: Review of Palaeobotany and Palynology, v. 93, p. 9-22.

Sun, S., and ZHU, S., 2000, Paleoproterozoic eukaryotic fossils from northern China: Acta Geologica Sinica, v. 74, p. 116-122.

Talyzina, N.M., and MoczydŁowska, M., 2000, Morphological and ultrastructural studies of some acritarchs from the Lower Cambrian Lükati Formation, Estonia: Review of Palaeobotany and Palynology, v. 112, p. 1-21.

VIDAL, G., 1988, A palynological preparation method: Palynology, v. 12, p. 215-220.

Weiss, B.P., Vali, H., Baudenbacher, F.J., Kirschvink, J.L., Stewart, S.T., and Shuster, D.L., 2002, Records of an ancient Martian magnetic field in ALH84001: Earth and Planetary Science Letters, v. 201, p. 449-463.

Willman, S., 2009, Morphology and wall ultrastructure of leiosphaeric and acanthomorphic acritarchs from the Ediacaran of Australia: Geobiology, v. 7, p. 8-20.

Willman, S., and MoczydŁowsKa, M., 2007, Wall ultrastructure of an Ediacaran acritarch from the Officer Basin, Australia: Lethaia, v. 40, p. 111-123.

Willman, S., Moczydłowska, M., and Grey, K., 2006, Neoproterozoic (Ediacaran) diversification of acritarchs: A new record from the Murnaroo 1 drillcore, eastern Officer Basin, Australia: Review of Palaeobotany and Palynology, v. 139, p. 17-39.

Wirth, R., 2004, Focused Ion Beam (FIB): A novel technology for advanced application of micro- and nanoanalysis in geosciences and applied mineralogy: European Journal of Mineralogy, v. 16, p. 863-876.

WIRTH, R., 2009, Focused Ion Beam (FIB) combined with SEM and TEM: Advanced analytical tools for studies of chemical composition, microstructure and crystal structure in geomaterials on a nanometre scale: Chemical Geology, v. 261, p. 217-229.

Xiao, S., Knoll, A.H., Kaufman, A.J., Yin, L., and Zhang, Y., 1997, Neoproterozoic fossils in Mesoproterozoic rocks? Chemostratigraphic resolution of a biostratigraphic conundrum from the North China Platform: Precambrian Research, v. 84, p. 197-220.

YAN, Y., 1982, Schizofusa from the Chuanlinggou Formation of Changcheng System in Jixian County: Bulletin, Tianjin Institute of Geology and Mineral Resources, v. 6, p. 1-7.

YAN, Y., 1991, Shale-facies microflora from the Changzhougou Formation (Changcheng System) in Pangjiapu Region, Hebei, China: Acta Micropalaeontologica Sinica, v. 8, p. 183-195.

YAN, Y., 1995, Shale facies microfloras from lower Changcheng System in Kuancheng, Hebei, and comparison with those of neighboring areas: Acta Micropalaeontologica Sinica, v. 12, p. 349-373.

Yin, L., Zhu, M., Knoll, A.H., Yuan, X., Zhang, J., and Hu, J., 2007, Doushantuo embryos preserved inside diapause egg cysts: Nature, v. 446, p. 661-663.

ZANG, W.-L., 2007, Deposition and deformation of late Archean sediments and preservation of microfossils in the Harris Greenstone Domain, Gawler Craton, South Australia: Precambrian Research, v. 156, p. 107-124.

Zhang, Z., 1986, Clastic facies microfossils from the Chuanlinggou Formation (1800 Ma) near Jixian, North China: Journal of Micropalaeontology, v. 5, no. 2, p. 9-16.

ZhANG, Z., 1997, A new Palaeoproterozoic clastic-facies microbiota from the Changzhougou Formation, Changcheng Group, Jixian, north China: Geological Magazine, v. 134, p. 145-150.

ACCEPTED APRIL 24, 2009 